\title{
High rates of general practice attendance by former prisoners: a prospective cohort study
}

\author{
Megan Carroll', Matthew J Spittal', Anna R Kemp-Casey²,3, Nicholas G Lennox ${ }^{4}$, David B Preen ${ }^{5}$, Georgina Sutherland', \\ Stuart A Kinner ${ }^{1,6,7}$
}

The known Prisoners have complex health needs, and their use of tertiary health services and mortality after release are high. Improving access to primary care has been proposed as a strategy for improving their health.

The new In Queensland, former prisoners visited GPs at twice the rate of the general population. Attendance was higher among participants with a history of poor health or risky behaviour; that is, those more likely to have complex health needs.

The implications Increasing access to primary care to improve the health of former prisoners may be insufficient. Improving the quality, continuity, and cultural appropriateness of care is also needed.

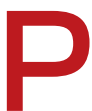
risoners are less healthy than the general population, ${ }^{1,2}$ and they have higher rates of chronic and infectious diseases. $^{2}$ Mental illness is also more prevalent; $38 \%$ of Australian prison entrants report having been told by a medical practitioner that they have a mental disorder, ${ }^{2}$ and the estimated 12-month prevalence of mental disorders among Australian prisoners is $80 \%$. $^{3}$ After release from custody, poor health outcomes place a significant burden on the affected individuals, their families, the health system, and the wider community. ${ }^{4}$

It has been suggested that not receiving appropriate primary care contributes significantly to the high rates of tertiary and acute service use by people recently released from prison. 5,6 Accordingly, a major component of many programs designed to improve their health outcomes is to increase their access to primary care. ${ }^{7}$ This approach assumes that rates of primary health care use by former prisoners are low, but little evidence supporting this view has been published. Several studies have documented high levels of primary care use in prison, ${ }^{8,9}$ but few have examined levels after release. ${ }^{10}$ One Australian study found that self-reported general practice attendance in the month after release from prison was an independent predictor of the subsequent use of specialist medical services. ${ }^{11}$ However, how often Australian former prisoners seek help from general practitioners after their release has not been investigated.

In this study, we analysed linked survey and routinely collected longitudinal administrative data to characterise GP encounters for a large cohort of adults after their release from prison. We compared rates of attendance with those of the general population, and identified factors associated with former prisoners consulting a GP.

\section{Methods}

We analysed data for a cohort of adults initially interviewed prior to their release from prison in Queensland. Data for these

\section{Abstract}

Objectives: To determine the rates at which people recently released from prison attend general practitioners, and to describe service users and their encounters.

Design, participants and setting: Prospective cohort study of 1190 prisoners in Queensland, interviewed up to 6 weeks before expected release from custody (August 2008 - July 2010); their responses were linked prospectively with Medicare and Pharmaceutical Benefits Scheme data for the 2 years after their release. General practice attendance was compared with that of members of the general Queensland population of the same sex and in the same age groups.

Main outcome measures: Rates of general practice attendance by former prisoners during the 2 years following their release from prison.

Results: In the 2 years following release from custody, former prisoners attended general practice services twice as frequently (standardised rate ratio, 2.04; $95 \% \mathrm{Cl}, 2.00-2.07$ ) as other Queenslanders; $87 \%$ of participants visited a GP at least once during this time. $42 \%$ of encounters resulted in a filled prescription, and $12 \%$ in diagnostic testing. Factors associated with higher rates of general practice attendance included history of risky opiate use (incidence rate ratio [IRR], 2.09; $95 \% \mathrm{Cl}$, 1.65-2.65), having ever been diagnosed with a mental disorder (IRR, 1.32; 95\% Cl, 1.14-1.53), and receiving medication while in prison (IRR, 1.82; 95\% Cl, 1.58-2.10).

Conclusions: Former prisoners visited general practice services with greater frequency than the general Queensland population. This is consistent with their complex health needs, and suggests that increasing access to primary care to improve the health of former prisoners may be insufficient, and should be accompanied by improving the quality, continuity, and cultural appropriateness of care.

participants were linked with routinely collected national and state administrative health care data for general practice encounters in the 2 years following their release. We compared rates of GP attendance for this cohort with rates for members of the general Queensland population of the same sex and in the same age groups.

The participants were 1325 adults interviewed up to 6 weeks before their expected release from one of seven prisons in Queensland during August 2008 - July 2010 (one person was released earlier than expected, in July 2008). They were recruited as part of a randomised controlled trial of a service brokerage intervention, and, except for the deliberate oversampling of females, were broadly representative of all adults released from prison in Queensland during the study period. The findings of the trial, together with further information about recruitment, the interview process, and the survey measures, have been published elsewhere. ${ }^{12}$

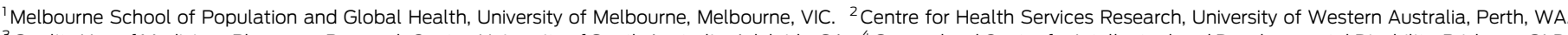

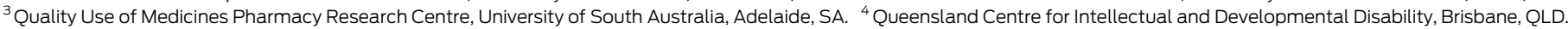

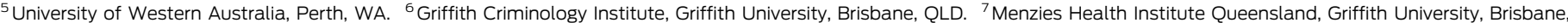
QLD. \@ m.carroll@student.unimelb.edu.au • doi: 10.5694/mja16.00841 


\section{Baseline measures}

Baseline interviews of about 90 minutes' duration collected information on the demographic characteristics of the participants, their physical and mental health, historical and current substance misuse, and social support. Participants were asked about their current relationship status, whether they had had any visitors during the previous 4 weeks, the number of years of schooling they had completed, and their accommodation (stable $v$ insecure) and employment status (full-time or part-time $v$ not employed) before their incarceration. Other self-reported measures included current smoking status, history of injecting drug use, and lifetime diagnoses of a mental disorder or chronic illness.

We applied several validated measures to assess risky substance use prior to incarceration, ${ }^{12}$ including the Alcohol Use Disorders Identification Test (AUDIT) ${ }^{13}$ and the Alcohol, Smoking and Substance Involvement Screening Test (ASSIST) ${ }^{14}$ for assessing illicit drug use. Scores on each measure were categorised according to standard cut-offs and dichotomised in order to compare the highest level of risk with all other levels combined. Current psychological distress was measured with the Kessler Psychological Distress Scale (K10), ${ }^{15}$ and the results were dichotomised into low/moderate and high/very high distress levels. A participant was deemed as potentially having an intellectual disability if their score on the Hayes Ability Screening Index $\left(\mathrm{HASI}^{16}\right)$ was below the standard threshold of 85 , and they reported that they had ever been diagnosed with an intellectual disability or had attended a special school. ${ }^{17}$ Incarceration history and length of the most recent incarceration were obtained from correctional institution records. Details of current prescribed medications were obtained from prison medical records for participants who consented to providing this information, and exposure to hepatitis $\mathrm{C}$ virus (HCV) was defined by a selfreport of exposure or a positive $\mathrm{HCV}$ antibody test result recorded in prison medical records.

\section{Linked administrative data}

Primary care attendance data were obtained for consenting participants through probabilistic linkage with Medicare Benefits Schedule (MBS) claims data. Pharmaceutical Benefits Scheme (PBS) claims data were used for identifying publicly subsidised prescription medicines dispensed to participants. MBS and PBS data were available for the 2 years following release from custody (the period July 2008 - June 2012).

Dates of re-incarceration for participants who returned to prison during follow-up were provided by Queensland Corrective Services (QCS). Participants who died during follow-up were identified by probabilistic linkage with the National Death Index.

\section{Population data}

We obtained aggregated MBS data for Queensland covering the study period, stratified by age and sex, from the publicly available Medicare database (http://medicarestatistics.humanservices.gov. $\mathrm{au} /$ statistics/mbs_item.jsp). As MBS item numbers 23 (standard GP consultation of less than 20 minutes), 36 (extended GP consultation) and 5020 (standard GP consultation, after hours) accounted for $82 \%$ of GP encounters with former prisoners, we restricted our analysis to these items.

\section{Data analysis}

Population comparisons. Crude rates of GP attendance per person-year were calculated according to MBS item numbers 23,36 and 5020, after deducting subsequent time in prison (and consequent exclusion from Medicare) and censoring at death. The rates were not corrected for multiple encounters on the same day, as this could not be applied to the population data. Participant ages were grouped into 10-year categories to match the format of the population data. The attendance rates were compared with general population rates, and age- and sexstandardised rate ratios (SRRs) calculated, using indirect standardisation.

Encounter characteristics and regression analyses. Primary care encounters were defined by MBS item descriptions. In addition to all services directly provided by GPs, those performed by a practice nurse or Indigenous health worker on behalf of a GP (eg, immunisations) were defined as GP attendances. If there were several encounters with the same provider on the same date, they were counted as a single occurrence. To assess continuity of care, participants were considered to have a primary provider if they had had more than one GP encounter and at least $50 \%$ of their encounters were with the same provider. Encounters were considered to include a diagnostic test if it was ordered on the same date as a GP attendance by the same provider. As provider identification was encrypted separately in the PBS and MBS data, it could not be matched across datasets. Encounters were therefore considered to include an associated prescription if the participant had a PBS record with a prescription date matching the date of an encounter with a GP.

We used negative binomial regression to identify characteristics associated with higher rates of GP contact. Unadjusted incidence rate ratios (IRRs) were calculated (with 95\% confidence intervals [CIs]), and a multivariate model was built by backwards elimination of covariates for which $P>0.05$. Given the potential interactions between variables, all were included in the initial multivariate model. We adjusted for intervention group during model construction, but as there were no significant differences between groups, we elected not to include the intervention as a covariate, in order to preserve statistical power. Analyses were conducted in Stata 13.1 (StataCorp) and Excel 2013 (Microsoft).

\section{Ethics approval}

Ethics approval for collecting the baseline data was provided by the University of Queensland Behavioural and Social Sciences Ethical Review Committee (reference, 200700607) and the QCS Research Committee. Approval to link the baseline data to MBS and PBS data was provided by the Australian Department of Human Services (reference, 2011/CO08902); the Australian Institute of Health and Welfare Ethics Committee approved linkage to the National Death Index (reference, EC 2012/4/58).

\section{Results}

Of the 1325 participants interviewed, data for 1190 (89.8\%) could be linked with both Medicare/PBS and QCS records and were therefore included in the analyses described in this article. With the exception that a higher proportion of female participants consented to participate ( $94 \%$ v $89 \%$ for men), there were no significant differences between the baseline characteristics of those with and without linked records. Most participants were men (78\%), 61\% were aged 25-44 years, and $25 \%$ identified as Aboriginal and/or Torres Strait Islander people. Participants reported high rates of chronic illness, risky substance use, and psychological distress (Box 1). 
1 Characteristics of the 1190 participants with linked interview, Medicare, Pharmaceutical Benefits Scheme and Queensland Corrective Services data at baseline

\begin{tabular}{|c|c|}
\hline Characteristic & Number (\%) \\
\hline \multicolumn{2}{|l|}{ Age (years) } \\
\hline$<25$ & $297(25 \%)$ \\
\hline $25-44$ & $724(61 \%)$ \\
\hline$\geq 45$ & $169(14 \%)$ \\
\hline Sex (women) & $262(22 \%)$ \\
\hline Identified as Indigenous Australians & $294(25 \%)$ \\
\hline Days in prison, median (interquartile range) & $175(88-341)$ \\
\hline Previous imprisonment as an adult & $774(65 \%)$ \\
\hline Married/de facto relationship & $414(35 \%)$ \\
\hline Social visitors in prison* & $557(47 \%)$ \\
\hline Schooling, $\geq 10$ years & $680(57 \%)$ \\
\hline Employed $^{\dagger}$ & $887(74 \%)$ \\
\hline Stable accommodation ${ }^{\dagger}$ & $991(83 \%)$ \\
\hline \multicolumn{2}{|l|}{ Health-related factors } \\
\hline Intellectual disability $(N=1165)$ & $112(10 \%)$ \\
\hline High/very high psychological distress (K10 score $\geq 22$ ) & $314(27 \%)$ \\
\hline Ever diagnosed with mental illness & $521(44 \%)$ \\
\hline Ever diagnosed with chronic illness & $803(67 \%)$ \\
\hline Received medication in prison $(N=1153)$ & $533(46 \%)$ \\
\hline Hepatitis C virus-seropositive & $319(27 \%)$ \\
\hline \multicolumn{2}{|l|}{ Health risk-related factors } \\
\hline Possible alcohol dependence (AUDIT) ${ }^{\dagger}$ & $333(29 \%)$ \\
\hline Current smoker & $929(78 \%)$ \\
\hline Ever injected drugs & $662(56 \%)$ \\
\hline Risky opiate use $(A S S I S T)^{\dagger}$ & $110(9 \%)$ \\
\hline Risky cannabis use $(\text { ASSIST) })^{\dagger}$ & $113(10 \%)$ \\
\hline Risky methamphetamine use (ASSIST) ${ }^{\dagger}$ & $140(12 \%)$ \\
\hline
\end{tabular}

ASSIST = Alcohol, Smoking and Substance Involvement Screening Test; AUDIT $=$ Alcohol Use Disorders Identification Test; $\mathrm{K} 10=$ Kessler Psychological Distress Scale. * During the past 4 weeks. † Prior to imprisonment.

\section{General practice visits by former prisoners: comparison with the general population}

Participants attended general practice services (MBS item numbers 23,36 and 5020) at twice the rate of the general population (SRR, $2.04 ; 95 \% \mathrm{CI}, 2.00-2.07)$. The rate for men aged $25-34$ years was 2.8 times that of other Queensland men of the same age (SRR, 2.83; 95\% CI, 2.74-2.92). GP attendance by male former prisoners increased with age (consistent with trends in the general community). There was no consistent increase with age among women (participants or the general population); among female former prisoners, the rate was highest for those aged 25-34 years (Box 2).

\section{Characteristics of GP encounters with former prisoners}

About $87 \%$ of participants had at least one contact with a GP in the 2 years following their release; more women had at least one contact (94\% $v 85 \%$ for men), and their median number of contacts was higher (women: median; 14; interquartile range [IQR], 6-26; men: median, 8; IQR, 3-17). The median time to the first GP encounter was longest for men under 25 years of age (101 days; IQR, 31-242 days), and was shortest for women over 25 (31 days; IQR,
6-122 days). About $42 \%$ of encounters resulted in prescriptions being filled. Encounters associated with diagnostic testing were nearly twice as common for young women as for older women or men of any age (21\% v $11-12 \%)$ (Box 3$)$.

\section{Predictors of GP encounters with former prisoners}

In adjusted analyses, rates of GP attendance were higher for older (per year: IRR, 1.01; 95\% CI, 1.01-1.02; $P<0.001$ ) and female participants (IRR, $1.35 ; 95 \%$ CI, 1.15-1.56; $P<0.001$ ), and lower for Indigenous participants (IRR, $0.76 ; 95 \% \mathrm{CI}, 0.64-0.89 ; P=0.001$ ). Other characteristics significantly associated with higher frequency of GP contact were health- or health risk-related, the strongest individual predictor being risky opiate use prior to imprisonment (IRR, 2.09; 95\% CI, 1.65-2.65; $P<0.001$ ) (Box 4).

\section{Discussion}

Our findings provide a valuable insight into how often people recently released from prison visit GPs. Although improving access to primary care has been considered as an approach for improving health outcomes in this population, ${ }^{10,18}$ we found that former prisoners attended GPs more frequently during the first 2 years after release than other Queenslanders. In particular, men aged 25-44 years - the vast majority of prisoners in Australia are in this age group ${ }^{19}$ - attended at a much higher rate than men in the same age group from the general community. The main characteristics associated with increased rates of contact were indicators of poor health or health risk, suggesting that the higher rates of GP attendance corresponded to greater need for health care.

As in the general population, being older was associated with more GP visits by former prisoners, as was being female. ${ }^{20}$ Appointments for young women in our cohort included diagnostic testing at nearly twice the rate for men and older women. Further exploration of the data revealed that testing was primarily associated with pregnancy and sexual health. Although we have no information on the results of these tests, this finding is encouraging, given the high rates of sexually transmitted infections in young women, particularly Indigenous Australian women. $^{21}$

The strong association between high risk opiate drug use and increased GP attendance is probably driven by the regular contact required by opioid substitution therapy. ${ }^{22}$ This finding contrasted with the lower frequency of GP visits associated with high risk methamphetamine and alcohol use by former prisoners. Risky use of either of these substances contributes to both poor health and re-offending, ${ }^{23,24}$ but without appropriate substitution therapies there is little incentive for users to be in regular contact with GPs. Although beyond the scope of this study, it would be of interest to know whether a lower frequency of GP visits by people who use drugs and alcohol at harmful levels is associated with higher use of emergency department and hospital services.

Our finding of lower rates of GP attendance by Indigenous Australians after release from prison is consistent with data for the general Indigenous community, ${ }^{21}$ and suggests that the health and social impacts of incarcerating Indigenous Australians might be exacerbated by infrequent visits to GPs after their release. Improving access to culturally appropriate primary care services may help to reduce this disparity and contribute to closing the gap in morbidity and life expectancy between Indigenous and nonIndigenous Australians. ${ }^{2}$ 
2 General practice attendance rates of former prisoners during the first 2 years after release from prison, compared with attendance among the general Queensland population

\begin{tabular}{|c|c|c|c|c|c|}
\hline \multirow[b]{2}{*}{ Age, years } & \multicolumn{2}{|c|}{ Study cohort* } & \multicolumn{2}{|c|}{$\begin{array}{c}\text { General Queensland } \\
\text { population }\end{array}$} & \multirow[b]{2}{*}{$\begin{array}{l}\text { Rate ratio } \\
(95 \% \mathrm{Cl})\end{array}$} \\
\hline & $\begin{array}{l}\text { GP visits } \\
\text { (number) }\end{array}$ & $\begin{array}{c}\text { Crude rate } \\
\text { (per } \\
\text { person-year) }\end{array}$ & $\begin{array}{l}\text { GP visits } \\
\text { (number) }\end{array}$ & $\begin{array}{c}\text { Crude rate } \\
\text { (per person-year) }\end{array}$ & \\
\hline \multicolumn{6}{|l|}{ Men } \\
\hline $15-24$ & 1195 & 3.48 & 2610618 & 2.12 & $\begin{array}{c}1.64 \\
(1.55-1.73)\end{array}$ \\
\hline $25-34$ & 3729 & 6.70 & 2907659 & 2.37 & $\begin{array}{c}2.83 \\
(2.74-2.92)\end{array}$ \\
\hline $35-44$ & 2513 & 7.00 & 3642003 & 2.80 & $\begin{array}{c}2.50 \\
(2.40-2.60)\end{array}$ \\
\hline $45-54$ & 1029 & 6.01 & 4274789 & 3.50 & $\begin{array}{c}1.72 \\
(1.61-1.83)\end{array}$ \\
\hline$\geq 55$ & 803 & 7.31 & 12743883 & 6.16 & $\begin{array}{c}1.19 \\
(1.11-1.27)^{\dagger}\end{array}$ \\
\hline $\begin{array}{l}\text { All men } \\
\geq 15 \text { years }\end{array}$ & 9269 & 6.02 & 26178952 & 3.64 & $\begin{array}{c}2.14 \\
(2.10-2.18)^{\dagger}\end{array}$ \\
\hline \multicolumn{6}{|l|}{ Women } \\
\hline $15-24$ & 769 & 6.52 & 4877618 & 4.10 & $\begin{array}{c}1.59 \\
(1.48-1.71)\end{array}$ \\
\hline $25-34$ & 1883 & 9.75 & 5510827 & 4.49 & $\begin{array}{c}2.17 \\
(2.08-2.28)\end{array}$ \\
\hline $35-44$ & 936 & 7.22 & 5710821 & 4.36 & $\begin{array}{c}1.66 \\
(1.55-1.77)\end{array}$ \\
\hline$\geq 45$ & 348 & 8.99 & 21296880 & 6.22 & $\begin{array}{c}1.44 \\
(1.30-1.60)\end{array}$ \\
\hline $\begin{array}{l}\text { All women } \\
\geq 15 \text { years }\end{array}$ & 4693 & 8.21 & 37396146 & 4.84 & $\begin{array}{c}1.83 \\
(1.77-1.88)^{\dagger}\end{array}$ \\
\hline Total & 13962 & 6.91 & 63575098 & 4.24 & $\begin{array}{c}2.04 \\
(2.00-2.07)^{\dagger}\end{array}$ \\
\hline
\end{tabular}

* Age categories are as defined in population data; all members of the study cohort were at least 18 years old. + Standardised rate ratios.
Earlier research found that GP encounters in areas with the greatest social disadvantage are typically briefer and more focused on prescribing medications. ${ }^{26}$ However, we found that $14 \%$ of encounters with former prisoners were longer than a standard consultation, and that $38 \%$ of participants had at least one extended encounter during the 2 years of follow-up. One in five of these extended consultations included development of a mental health plan (MBS item numbers 2700 to 2717) (data not shown). We also found that less than half of all GP encounters $(42 \%)$ resulted in a filled prescription, but without a corresponding figure for the general community this finding is difficult to interpret.

We found that former prisoners not only visit GPs more frequently than other Queenslanders, but also visit multiple care providers (median, 4; IQR, 2-6). We were unable to ascertain whether participants were attending appointments with different doctors in the same practice or providers at different locations. Although the effect of seeing different providers on continuity and quality of care in this population is unknown, it has been reported that continuity is associated with improved satisfaction with care, especially when chronic disease is being managed, ${ }^{27}$ and for more vulnerable patients. ${ }^{28}$ Further research is required to better understand the relationship between continuity of care and health outcomes for prisoners after their release, including investigation of how information is shared between health care providers, both in prison and in the community.

This is the first study to systematically examine rates and predictors of GP contact for people recently released from prison. There were, however, a number of limitations. First, as the Medicare and PBS data were collected for administrative purposes, we had no information about the specific reasons for health care encounters. Second, although we were able to identify records of diagnostic tests performed and prescriptions filled, we

3 Characteristics of encounters with a general practitioner during the 2 years following release from prison, by sex and age

\begin{tabular}{|c|c|c|c|c|c|}
\hline & Men $<25$ years & Men $\geq \mathbf{2 5}$ years & Women $<25$ years & Women $\geq 25$ years & All \\
\hline Number of participants & 233 & 695 & 64 & 198 & 1190 \\
\hline Any encounter with a general practitioner & $176(76 \%)$ & $609(88 \%)$ & $61(95 \%)$ & $186(94 \%)$ & $1032(87 \%)$ \\
\hline Days to first encounter, median (IQR)* & $101(31-242)$ & $43(8-158)$ & $55(10-132)$ & $31(6-122)$ & $50(8.5-166)$ \\
\hline Number of providers, median (IQR)* & $3(1-5)$ & $3(2-6)$ & $5(3-9)$ & $5(3-8)$ & $4(2-6)$ \\
\hline Any appointment longer than 20 minutes $^{\ddagger}$ & $100(43 \%)$ & $243(35 \%)$ & $16(25 \%)$ & $56(28 \%)$ & $364(38 \%)$ \\
\hline Total number of encounters & 1492 & 9968 & 950 & 3788 & 16188 \\
\hline Encounters resulting in filled prescriptions ${ }^{\S}$ & $417(29 \%)$ & $4313(44 \%)$ & $279(30 \%)$ & $1695(45 \%)$ & $6704(42 \%)$ \\
\hline Encounters with diagnostic tests ${ }^{\S}$ & $156(11 \%)$ & 1190 (12\%) & 195 (21\%) & $438(12 \%)$ & 1979 (12\%) \\
\hline
\end{tabular}

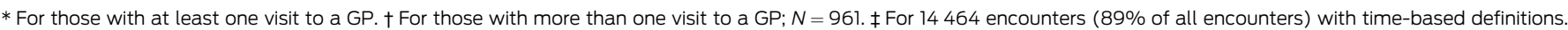
$\S$ Participants who had PBS and MBS records with matching dates. 
4 Characteristics significantly associated with an increased rate of general practice attendance; negative binomial regression*

\begin{tabular}{|c|c|c|c|c|}
\hline & \multicolumn{2}{|c|}{ Univariate model } & \multicolumn{2}{|c|}{ Multivariate model } \\
\hline & IRR (95\% CI) & $P$ & IRR $(95 \% \mathrm{Cl})$ & $P$ \\
\hline Age (per year) & $1.02(1.01-1.02)$ & $<0.001$ & $1.01(1.00-1.02)$ & $<0.001$ \\
\hline Sex (female) & $1.34(1.13-1.59)$ & 0.001 & $1.35(1.15-1.56)$ & $<0.001$ \\
\hline Identified as Indigenous Australian & $0.65(0.55-0.77)$ & $<0.001$ & $0.76(0.64-0.89)$ & 0.001 \\
\hline Previous imprisonment as adult & $1.20(1.04-1.40)$ & 0.008 & & \\
\hline Time in prison (per week) & $1.00(0.99-1.00)$ & 0.18 & & \\
\hline Married/de facto relationship & $1.08(0.94-1.26)$ & 0.35 & & \\
\hline Social visitors in prison & $0.92(0.79-1.06)$ & 0.22 & & \\
\hline Schooling, $\geq 10$ years & $0.97(0.83-1.11)$ & 0.69 & & \\
\hline Employed & $1.07(0.91-1.27)$ & 0.43 & & \\
\hline Stable accommodation & $0.90(0.74-1.09)$ & 0.31 & & \\
\hline \multicolumn{5}{|l|}{ Health-related factors } \\
\hline Intellectual disability & $0.98(0.77-1.26)$ & 0.56 & & \\
\hline High/very high psychological distress (K10 score $\geq 22$ ) & $1.37(1.17-1.61)$ & $<0.001$ & & \\
\hline Ever diagnosed with mental illness & $1.77(1.54-2.04)$ & $<0.001$ & $1.32(1.14-1.53)$ & 0.001 \\
\hline Ever diagnosed with chronic illness & $1.42(1.22-1.66)$ & $<0.001$ & $1.20(1.04-1.39)$ & 0.049 \\
\hline Medication in prison & $2.15(1.87-2.47)$ & $<0.001$ & $1.82(1.58-2.10)$ & $<0.001$ \\
\hline Hepatitis C virus-seropositive & $1.90(1.62-2.22)$ & $<0.001$ & $1.33(1.12-1.60)$ & $<0.001$ \\
\hline \multicolumn{5}{|l|}{ Health risk-related factors } \\
\hline Possible alcohol dependence (AUDIT) & $0.71(0.61-0.84)$ & $<0.001$ & $0.79(0.68-0.93)$ & 0.009 \\
\hline Current smoker & $1.11(0.93-1.31)$ & 0.19 & & \\
\hline Ever injected drugs & $1.66(1.44-1.91)$ & $<0.001$ & $1.34(1.14-1.58)$ & 0.002 \\
\hline Risky opiate use (ASSIST) & $2.68(2.12-3.39)$ & $<0.001$ & $2.09(1.65-2.65)$ & $<0.001$ \\
\hline Risky cannabis use (ASSIST) & $0.85(0.66-1.09)$ & 0.14 & & \\
\hline Risky methamphetamine use (ASSIST) & $0.99(0.79-1.24)$ & 0.58 & $0.71(0.58-0.88)$ & $<0.001$ \\
\hline
\end{tabular}

ASSIST = Alcohol, Smoking and Substance Involvement Screening Test; AUDIT = Alcohol Use Disorders Identification Test; IRR = incidence rate ratio; $\mathrm{K} 10=\mathrm{Kessler}$ Psychological Distress Scale. $* N=1138$. Participants with missing data (see Box 1) were omitted from analyses.

were unable to determine when tests were recommended but not undertaken, or medications prescribed but not obtained. Our comparisons of rates with those of the general population were limited by the fact that publicly available data are stratified only by age group and sex. The effect of other potential confounders, such as Indigenous and socio-economic status, could, however, be explored within our cohort. Finally, we may have underestimated the prescribing of medications because prescriptions dispensed to "general beneficiaries" at prices below the co-payment threshold (in 2012, \$35.40) were not captured in the dataset. However, the impact of this limitation is probably small, given that most people leaving prison will not be employed immediately after release, and are therefore eligible for concessional benefits. ${ }^{2}$

\section{Conclusion}

It is often assumed that increasing the access to or contact with primary care services is important for reducing the high rates of mortality and acute and tertiary health care use by former prisoners. We found that former prisoners in Queensland visit GPs more frequently than other Queenslanders of their age and sex. We also found that those who visited GPs frequently often had complex substance misuse and mental health disorders, and thus have the greatest need for high quality, well coordinated health care.

Acknowledgements: We thank Queensland Corrective Services for assistance with data collection, and Passports study participants for sharing their stories. We acknowledge the Australian Government Department of Human Services as the source of Medicare and Pharmaceutical Benefits Scheme (PBS) records. The Passports study was funded by a National Health and Medical Research Council (NHMRC) Strategic Award (409966). The HIP-Aus study is funded by a National Health and Medical Research Council Project grant (1002463). Stuart Kinner is supported by an NHMRC Senior Research Fellowship (APP1078168). The views expressed in this article are solely those of the authors, and in no way reflect the views or policies of Queensland Corrective Services.

Competing interests: No relevant disclosures.

Received 14 July 2016, accepted 3 Jan 2017.

(c) 2017 AMPCo Pty Ltd. Produced with Elsevier B.V. All rights reserved.
1 Fazel S, Baillargeon J. The health of prisoners. Lancet 2011; 377: 956-965.

2 Australian Institute of Health and Welfare. The health of Australia's prisoners 2012 (AIHW Cat. No. PHE 170). Canberra: AlHW, 2013.
3 Butler T, Andrews G, Allnutt S, et al. Mental disorders in Australian prisoners: a comparison with a community sample. Aust N Z J Psychiatry 2006; 40: 272-276.

4 Kinner SA, Wang EA. The case for improving the health of ex-prisoners. Am J Public Health 2014; 104 1352-1355.
5 Frank J, Linder J, Becker W, et al. Increased hospital and emergency department utilization by individuals with recent criminal justice involvement: results of a national survey. J Gen Intern Med 2014; 29: 1226-1233.

6 Alan J, Burmas M, Preen D, Pfaff J. Inpatient hospital use in the first year after release from prison: a Western 
Australian population-based record linkage study. Aust N Z J Public Health 2011; 35: 264-269.

7 Kinner SA, Young JT, Carroll M. The pivotal role of primary care in meeting the health needs of people recently released from prison. Australas Psychiatry 2015; 23: 650-653.

8 Feron J, Paulus D, Tonglet R, et al. Substantial use of primary health care by prisoners: epidemiological description and possible explanations. J Epidemiol Community Health 2005; 59: 651-655.

9 Marshall T, Simpson S, Stevens A. Use of health services by prison inmates: comparisons with the community. J Epidemiol Community Health 2001; 55: 364-365.

10 Wang EA, Hong CS, Shavit S, et al. Engaging individuals recently released from prison into primary care: a randomized trial. Am J Public Health 2012; 102: e22-e29.

11 Young JT, Arnold-Reed D, Preen D, et al. Early primary care physician contact and health service utilisation in a large sample of recently released ex-prisoners in Australia: prospective cohort study. BMJ Open 2015; 5: e008021.

12 Kinner SA, Alati R, Longo M, et al. Low-intensity case management increases contact with primary care in recently released prisoners: a single-blinded, multisite, randomised controlled trial. J Epidemiol Community Health 2016; 70: 683-688.

13 Babor TF Higgins-Biddle JC, Saunders JB, Monteiro MG. AUDIT. The Alcohol Use Disorders Identification Test: guidelines for use in primary care. 2nd edition. Geneva: World Health Organization, 2001. http://apps.who. int/iris/bitstream/10665/67205/1/WHO_MSD_MSB_ 01.6a.pdf (accessed May 2017).

14 WHO ASSIST Working Group. The Alcohol, Smoking and Substance Involvement Screening Test (ASSIST): development, reliability and feasibility. Addiction 2002; 97: 1183-1194.

15 Kessler RC, Andrews G, Colpe LJ, et al. Short screening scales to monitor population prevalences and trends in non-specific psychological distress. Psychol Med 2002; 32: 959-976.

16 Hayes SC. Early intervention or early incarceration? Using a screening test for intellectual disability in the criminal justice system. J Appl Res Intellect Disabil 2002 15: 120-128.

17 Dias S, Ware RS, Kinner SA, Lennox NG. Physical health outcomes in prisoners with intellectual disability: a cross-sectional study. J Intellect Disabil Res 2013; 57: 1191-1196.

18 Mai Q, Holman CD, Sanfilippo FM, et al. Do users of mental health services lack access to general practitioner services? Med J Aust 2010; 192: 501-506. https://www.mia.com.au/journal/2010/192/9/do-usersmental-health-services-lack-access-generalpractitioner-services

19 Australian Bureau of Statistics. 4517.0. Prisoners in Australia 2011. Dec 2011. http://www.abs.gov.au/ AUSSTATS/abs@.nsf/Lookup/4517.0Main+Features 12011?OpenDocument (accessed May 2017).

20 Britt H, Miller GC, Henderson J, et al. General practice activity in Australia 2013-14 (General Practice Series No. 36). Sydney: Sydney University Press, 2014. https://ses. library.usyd.edu.au/bitstream/2123/11882/4/ 9781743324226 ONLINE.pdf (accessed May 2017).

21 The Kirby Institute. HIV, viral hepatitis and sexually transmissible infections in Australia: annual surveillance report 2013. Sydney: The Kirby Institute, The University of New South Wales, 2013. https://kirby.unsw.edu.au/
sites/default/files/kirby/report/SERP_2013-AnnualSurveillance-Report.pdf (accessed May 2017)

22 Queensland Health. Queensland opioid treatment program: clinical guidelines 2012. Brisbane: Queensland Health, 2012. https://www.health.qld.gov.au/_data/ assets/pdf_file/0022/444613/qotp-clinical-guidelines. pdf (accessed May 2017).

23 Håkansson A, Berglund M. Risk factors for criminal recidivism - a prospective follow-up study in prisoners with substance abuse. BMC Psychiatry 2012; 12: 11.

24 Winter RJ, Stoové M, Degenhardt L, et al. Incidence and predictors of non-fatal drug overdose after release from prison among people who inject drugs in Queensland, Australia. Drug Alcohol Depend 2015; 153: 43-49.

25 Hayman NE, White NE, Spurling GK. Improving Indigenous patients' access to mainstream health services: the Inala experience. Med J Aust 2009; 190: 604-606. https://www.mja.com.au/journal/2009/190/ 10/improving-indigenous-patients-access-mainstreamhealth-services-inala-experience

26 Furler JS, Harris E, Chondros $\mathrm{P}$, et al. The inverse care law revisited: impact of disadvantaged location on accessing longer GP consultation times. Med J Aust 2002; 177: 80-83. https://www.mja.com.au/journal/2002/177/2/ inverse-care-law-revisited-impact-disadvantagedlocation-accessing-longer-gp

27 Health Quality Ontario. Continuity of care to optimize chronic disease management in the community setting an evidence-based analysis. Ont Health Technol Assess Ser 2013; 13: 1-41.

28 Nutting PA, Goodwin MA, Flocke SA, et al. Continuity of primary care: to whom does it matter and when? Ann Fam Med 2003; 1: 149-155. 